\title{
Hedgehog Pathway Mutation
}

National Cancer Institute

\section{Source}

National Cancer Institute. Hedgehog Pathway Mutation. NCI Thesaurus. Code C148101.

A change in the sequence of one or more genes that are involved in the hedgehog signaling pathway. 